\title{
ERRATUM, VOLUME 68
}

François Treves, The equation

$$
\left(\partial^{2} / \partial x^{2}+\partial^{2} / \partial y^{2}+\left(x^{2}+y^{2}\right)(\partial / \partial t)\right)^{2} u+\partial^{2} u / \partial t^{2}=f,
$$

with real coefficients, is "without solutions," p. 332.

The title should read:

The equation

$$
\begin{gathered}
\left(\frac{1}{4}\left(\partial^{2} / \partial x^{2}+\partial^{2} / \partial y^{2}\right)+\left(x^{2}+y^{2}\right) \partial^{2} / \partial t^{2}+(x \partial / \partial y-y \partial / \partial x) \partial / \partial t\right)^{2} u \\
+\partial^{2} u / \partial t^{2}=f,
\end{gathered}
$$

with real coefficients, is "without solutions."

Annual Meeting in Cincinnati, p. 187.

In the list of new members, Dr. Bob van Rootselaar was incorrectly listed as Professor van Rootselaar. This correction is being made at his request.

\section{ADDENDUM}

In the article Holomorphic fiber bundles over Riemann surfaces by Helmut Röhrl, May, 1962 an oversight caused omission of the following acknowledgement: "This research was sponsored by the Air Force Office of Scientific Research." 